\title{
Enação e processo de trabalho: uma abordagem atuacionista da ação operatória
}

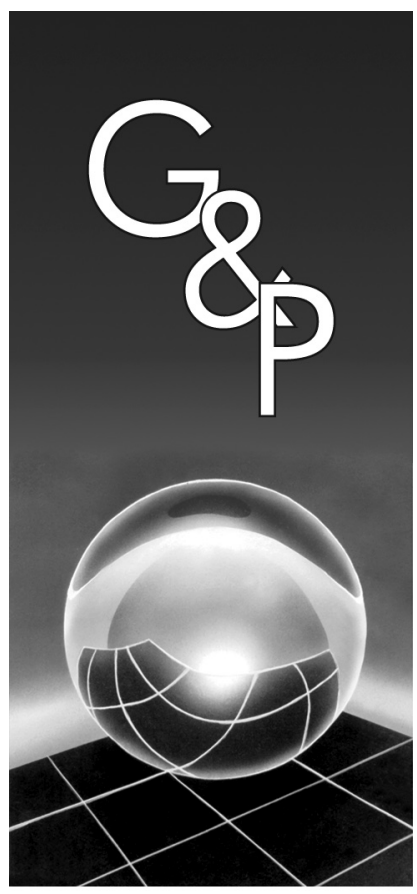

Gilbert Cardoso Bouyer

Laerte Idal Sznelwar

\section{Resumo}

Este artigo, baseado no novo paradigma das ciências cognitivas, convida a uma ruptura ontológica com a abordagem objetivista da representação operatória em Ergonomia Cognitiva. O atuacionismo é um ponto de vista incorporado-enativo. Ou seja, processos cognitivos emergem ou en-agem pelos agentes (trabalhadores). A abordagem atuacionista pode fornecer significativas contribuições à Ergonomia. Este trabalho é o resultado de pesquisa realizada em sistemas reais de produção, pelos métodos de Análise Ergonômica do Trabalho. Ele identificou e caracterizou uma falha ontológica, presente nas análises da atividade operatória: Observador isolado do objeto observado pelas distinções de atuação entre ambos. Isso resulta em diferenças de ação, percepção e interpretação, as quais, historicamente, têm tornado impraticável um conhecimento aprofundado sobre o funcionamento do processo de trabalho. Atualmente, os processos que aparentam ser rotineiros, parcelados e manuais abrigam uma nova noção de competência, a competência atuacionista ou cognitiva, necessária para conferir continuidade e fluxo à produção.

Palavras-chave: Enação. Ergonomia cognitiva. Ação incorporada.

\section{Introdução}

Sob quais bases conceituais e teóricas é possível, nos sistemas de produção dos dias atuais, rotular, como desqualificado, um trabalho "parcelado e rotineiro, baseado na especialização parcelada das tarefas" (GORZ, 2001)?

Por que este tipo de trabalho "insiste" em "permanecer vivo" na atualidade, inclusive no interior das "novas formas" de Organização do Trabalho, baseadas em Células de Produção e Times dotados de certa autonomia? Célula baseada na especialização parcelada de Gorz (op. cit.), com tarefas parceladas individuais, manuais e rotineiras? Que mistura de antagonismos é esta? Que "modelo" é este? Que país é este?

Essas "novas formas..." não representariam uma ruptura com o "velho modelo" clássico de organização do trabalho? Por que, então, o "dinossauro" permanece vivo em solo nacional, ativo e em pleno vigor, nos sistemas de produção de algumas organizações líderes de mercado em seus segmentos? Por que ele, aqui, se reveste de novos nomes vindos da Europa e de países como Japão e Suécia?

A noção de competência, tão difundida como um componente imprescindível aos modernos sistemas de produção "integrados" e "flexíveis", estaria ausente nos processos de trabalho "rotineiros e parcelados"? Caso a resposta seja negativa, como, então, se materializa a competência nesses processos, uma vez que o modelo de organização do trabalho a eles inerente é a divisão do trabalho por "especialização parcelada das tarefas" (GORZ, op. cit.)?

Mesmo com toda inovação no tocante aos processos de trabalho, envolvendo novos modelos com flexibilidade organizacional e tecnológica (automação microeletrônica), vários sistemas produtivos, no Brasil, em sua essência, estão distantes dessas "novidades" de Organização do Trabalho. Uma constatação, portanto, de que na atualidade caracterizada pelas inovações organizacionais, processos de trabalho estão configurados, ainda, nos moldes clássicos.

O presente trabalho também se deparou com este fato, conforme discutido nessas linhas, uma vez que as três plantas industriais investigadas, fornecedoras de autopeças para o Mercosul e para as líderes de mercado no segmento automotivo brasileiro, possuem suas bases produtivas assentadas em processos de trabalho "manuais" e parcelados. Duas delas, inclusive, utilizam o "modelo" de Organização do Trabalho baseado em Células de Produção sem, entretanto, romperem com as rotinas baseadas na especialização parcelada e na fragmentação individualizada das tarefas, traços típicos do modelo taylorista clássico. 
Tais questões adquiriram uma gravidade maior. Não apenas pelo seu acentuado contraste em relação ao belo quadro pintado pelas vastas digressões sobre autonomia, iniciativa e habilidades de comunicação, abstração e manipulação simbólica demandadas pelos modernos cenários produtivos. Cenários permeados pelas novas tecnologias flexíveis de base microeletrônica e pelas inovadoras formas de organização do trabalho que se pautam pelo trabalho em equipe e pela desestabilização das tradicionais noções de: posto de trabalho; co-presença; e dissociação prescrição/execução (ZARIFIAN, 1999).

A gravidade maior adquirida pelas questões anteriormente levantadas adveio de um fato intrigante, oferecido pela realidade da produção das três fábricas de componentes para a indústria automobilística que produzem tanto para o mercado nacional quanto para exportação (Mercosul e Europa): Elas conseguem funcionar num rigoroso contexto posto por uma "rede de suprimentos", em que a noção de "just-intime externo" coloca rígidas exigências de flexibilidade e de integração para atender à cadeia de "suprimento enxuto" (LAMMING, 1993), interligada on-line por "sistemas de informação gerencial" SIG (Management Information Systems - MIS). Entretanto, no cerne destes três sistemas de produção pesquisados, permanecem, como essenciais, os processos de trabalho parcelados, rotineiros e repetitivos, baseados na especialização parcelada. Há, portanto, uma incoerência entre forma e conteúdo... Entre fins e meios.

Buscou-se, aqui, entender como um conteúdo interno aos sistemas, rotulado como essencialmente "desqualificado", objetivamente pautado pelas características do modelo clássico de organização do trabalho, é capaz de gerar desempenho (eficiência, eficácia) típico dos sistemas automatizados flexíveis, integrados e que, teoricamente, pressuporiam a competência, a iniciativa, a autonomia e a primazia do trabalho em equipe sobre o trabalho individual parcelado.

O que se propõe a discutir, neste espaço, é como se pode explicar a competência (macro...) dessas organizações, se na dimensão micro (competências individuais, processo de trabalho) ainda reinam as características do modelo clássico. Ou seja, como essas organizações, líderes em seus mercados, são capazes de se manterem, de forma eficiente, interligadas a um sistema maior, configurado por uma rede em que exuberam modernas tecnologias de informação e de planejamento e controle dos fluxos produtivos interdependentes se, aparentemente, são precárias no que se refere ao processo de trabalho, i.e. competências individuais.

A competência macro está comprovada pelo desempenho típico de organizações integradas e flexíveis que atendem às demandas determinadas pelo cenário exterior que lhes abarca ("enxuto" e produtivo a "tempo real"). Entretanto, na dimensão micro, verifica-se a predominância de tarefas individuais, parceladas, rotineiras e de base manual. Que competência, neste domínio, correlaciona-se ao desempenho flexível destas organizações produtivas?

\section{Delimitação do presente problema de pesquisa}

Há habilidades envolvidas no trabalho parcelado que não são percebidas por um observador externo. O observador não percebe o real conteúdo do trabalho parcelado porque permanece em outro domínio ontológico de distinções (MATURANA; VARELA, 1994). Além disso, os trabalhadores não conseguem explicar suas habilidades porque não conhecem a linguagem técnica dos engenheiros e a linguagem gerencial dos administradores que planejam o trabalho.

Os trabalhadores estão presos em seu mundo fechado de trabalho manual. Um mundo cheio de códigos próprios, linguagens particulares: $\mathrm{O}$ mundo cheio de "habilidades de percepção" resultantes da "embodied action" (VARELA; THOMPSON; ROSCH, 1993) no processo de trabalho manual. Mundo de percepções e trocas que não são captadas pelos engenheiros e pelos administradores do trabalho: Quem planeja o trabalho não enxerga a essência cognitiva escondida no trabalho parcelado porque está em outro "mundo de atuação". Os trabalhadores não conseguem explicar as suas próprias habilidades reais. Não existe alguém que possa compreender as habilidades escondidas no trabalho parcelado, porque somente quem está atuante no processo parcelado consegue perceber as mesmas coisas que os trabalhadores percebem. Neste texto, estas habilidades reais do trabalho parcelado serão definidas como "habilidades atuacionistas".

As habilidades reais do trabalho parcelado, ou habilidades atuacionistas, não são facilmente visíveis. Aqui, será utilizada a expressão "competência cognitiva" para definir o conjunto dessas habilidades associadas às percepções e ações que existem escondidas no trabalho parcelado. É a competência cognitiva ou "competência atuacionista" que explica a tendência de continuidade e a flexibilidade das empresas pesquisadas neste trabalho. São empresas brasileiras fabricantes de componentes para a indústria automobilística. Essas fábricas conseguem funcionar com continuidade e flexibilidade, dentro do sistema just-in-time, embora seus processos de trabalho sejam parcelados, manuais, rotineiros e precários. Como isso pode ser explicado?

Há uma competência no trabalho manual que justifica a eficiência de fábricas tayloristas que operam dentro do sistema just-in-time. Que competência é esta? O que ela esconde dentro de si? É a competência cognitiva, dependente da atuação ("embodiment...") do operador na sua tarefa, no seu trabalho, no seu mundo pouco compreendido. A tarefa solicita o seu corpo, os seus movimentos. A consequiência de atuar com o corpo, com os gestos 
sensório-motores, segundo Jackendoff (1987), é a ativação de um conjunto de percepções que não são as mesmas dos profissionais que planejam o trabalho.

Quando ocorre um acidente, uma pane, um defeito, uma quebra de máquina, um problema de matéria-prima, etc., o que acontece? Torna-se difícil estabelecer uma compreensão recíproca porque não há consenso na linguagem. E não há uma linguagem comum entre os que planejam o trabalho e os que executam o trabalho. Há uma lacuna entre os domínios de planejamento e execução, conforme mostra a Figura 1. E, também, quem planeja e gerencia o trabalho não percebe as coisas que quem executa o trabalho percebe, e vice-versa. Estão "atuando em mundos distintos" (VARELA, 2000). Quem executa os gestos manuais não consegue dizer o que ocorre em seu corpo, em sua mente, em sua cognição, em sua atividade. Quem falhou? Quem errou? Quem cometeu distração ou negligência?

Não existe falha. Não existe erro humano. Não existe distração. Não existe negligência. Existe dificuldade em compreender o ponto de vista do trabalhador. Nesta pesquisa, algumas situações que foram reconstituídas sob o ponto de vista do trabalhador revelaram que, na situação da ação, não ocorreu falha. Não ocorreu erro humano. Ocorreu, na realidade, uma ação que era a única possível, de acordo com as percepções que o trabalhador possuía. $\mathrm{E}$, apenas o trabalhador teve aquelas percepções. Mais ninguém as teve. Por isso, ninguém consegue entender porque ele agiu de uma determinada forma e não de outra. É necessário atuar na situação do trabalhador, compartilhar de seu mundo de percepções particulares, de seu mundo de trabalho parcelado, de seu mundo de gestos, mundo de movimentos específicos de seu corpo, para perceber as mesmas coisas que ele percebe. O problema é que ninguém, nem o observador do planejamento, nem o observador da ciência, conseguem atuar no "mundo de ação do trabalhador", o seu "mundo de percepções particulares": Sua atuação, seu "embodiment" (PETITOT et al., 2000). A atuação depende de uma história dentro do processo de trabalho. História que desenvolve estruturas sensório-motoras (JACKENDOFF, 1987) que "situam" o corpo na atividade e, portanto, desencadeiam o desen- volvimento de uma série de habilidades de percepção na ação incorporada ou "embodied action" (VARELA; THOMPSON; ROSCH, 1993).

O corpo que atua na tarefa parcelada determina o que vai ser percebido no trabalho. A percepção depende do corpo (MERLEAU-PONTY, 1976). O problema da influência do corpo na cognição do trabalhador, no seu trabalho cognitivo, foi pouco abordado até hoje. A ergonomia precisa compreender como o "movimento do corpo afeta as percepções" (MERLEAU-PONTY, op. cit.) do trabalhador em situação de trabalho. Isso pode ajudar a compreender porque ocorrem alguns desvios de qualidade nos produtos, e que "passam despercebidos" e, também, porque ocorrem alguns acidentes e eventos (panes, interrupções, desvios de qualidade) "inexplicáveis".

Além disso, os trabalhos parcelados que parecem ser simples são, na realidade, complexos. Eles demandam habilidades que só são adquiridas com uma longa história de atuação na tarefa em questão. Essas habilidades dependem do desenvolvimento de uma extensa rede de mecanismos sensório-motores ativados durante uma tarefa específica, fazendo emergir um "comportamento habilidoso" ou um "ato de habilidade". Nestas situações, a ação encontra-se perfeitamente integrada ao contexto da situação de trabalho, havendo uma harmonia entre o ato de trabalho, o instrumento de trabalho e a percepção do agente. É o que Varela (2000) vai denominar de "transparency" (transparência) ou uma espécie de visão de conjunto: Uma apreensão em conjunto, que harmoniza o instrumento e o ato num complexo perceptivo que depende da atuação corporal no processo de trabalho.

Numa das fábricas pesquisadas, que fabrica peças para as carrocerias de veículos de transporte de passageiros, o trabalho exige perceber pequenos indícios de falhas, ou pequenos indícios de defeitos nas peças. É um trabalho de percepção. Quando o trabalhador foi imobilizado num posto de trabalho projetado para facilitar o seu trabalho, com cadeira confortável, giratória, e farta iluminação, os índices de peças embaladas com vários defeitos aumentaram. Antes dessa situação, o trabalhador se movimentava pela esteira, carregava a peça em suas mãos, movimen-

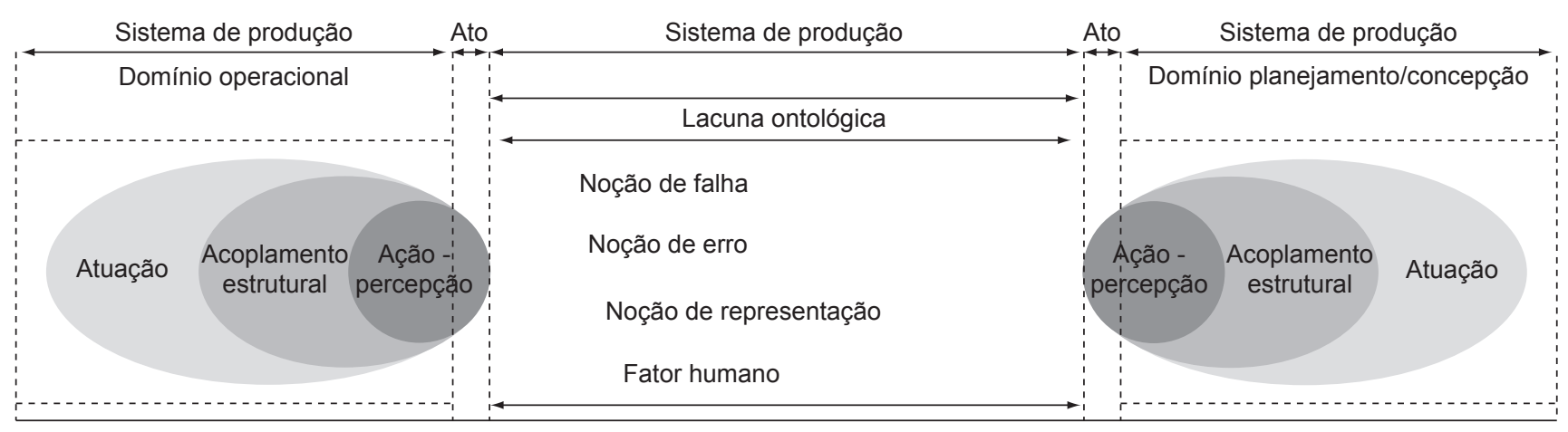

Figura 1. A falha ontológica e os mundos paralelos sem conexão. 
tava as peças com seus braços, girava as peças como bem quisesse. Esses movimentos do seu corpo eram importantes para ativar estruturas perceptivas que ficaram inativas no novo posto de trabalho. Há, portanto, uma competência particular que depende do corpo. Uma competência que depende da atuação "corporal" ou "embodied acts", do trabalhador em sua tarefa.

Quando este trabalhador enxergava, numa pequena parte da peça, um indício de defeito, a equipe de pesquisa marcava, com tinta, esta parte da peça que estava com defeito. Ao mostrar a peça para o engenheiro, o engenheiro observava atentamente, inclusive com o auxílio de uma lupa, o ponto marcado. Após observar a peça atentamente, o engenheiro afirmava que ela estava perfeita. $\mathrm{O}$ trabalhador do trabalho parcelado dizia que esta mesma peça estava defeituosa. Quem estava com a razão? O engenheiro? O trabalhador? Quem estava certo? Porque ocorria esta diferença de percepção?

Porque o trabalhador e o engenheiro atuam em mundos distintos. Portanto, percebem coisas distintas. Não percebem as mesmas coisas porque agem de modos diferentes, executam coisas diferentes, possuem histórias diferentes, enxergam um mesmo objeto de formas diferentes. Estão num mesmo mundo objetivo, mas também em diferentes mundos de atuação, diferentes em percepção e em ação. Diferentes, portanto, em cognição. O que se percebe possui caráter "emergente" e a emergência da habilidade perceptiva depende da atuação ou "embodiment" numa tarefa específica.

Ao testar a peça diretamente no automóvel, a equipe de pesquisa comprovou que havia um grave defeito de fabricação que não foi percebido pelo engenheiro e que só foi percebido pelo trabalhador.

O engenheiro usa uma linguagem técnica para explicar o fato. Somente ele entende a sua linguagem, e somente os demais engenheiros conseguem compreender o que ele diz. O trabalhador não entende nada do que ocorreu e não consegue explicar o fato. $\mathrm{O}$ trabalhador não entende porque o engenheiro não percebe a mesma coisa que ele percebe. Portanto, não há um consenso. Não há uma linguagem comum que funcione como uma ligação entre mundos que não se comunicam. Por isso, ocorrem interpretações incorretas sobre panes, falhas, defeitos, desvios, etc. Por que um percebeu o defeito e o outro não? Que mundos de percepções distintas são estes em que um não compartilha das mesmas percepções que o outro?

\section{Competência cognitiva dos operadores do trabalho parcelado}

Na realidade, existem certas distinções de linguagens e de percepções que impedem a intercompreensão entre diferentes atores envolvidos com as questões da produção. Mundos que não se interceptam pela falta de um código comum, e de um domínio comum de distinções, que permitam aos interlocutores se intercompreenderem.

Tais distinções são responsáveis pela falta de percepção da verdadeira natureza da competência em alguns modos específicos de organização do trabalho, levando os observadores a rotularem o conteúdo do processo de trabalho com termos que contradizem aquilo que é constatado pela observação científica.

Um trabalho é rotulado como "desqualificado", ou faltam elementos para caracterizar a presença de componentes de competência na sua execução porque os observadores mantêm-se (e historicamente se mantiveram) sem acesso aos domínios de distinções intangíveis, nos quais uma competência intangível, e um tipo de qualificação diferenciada, se manifestam.

Boa parte da explicação para esta falha ontológica é dada pelo fato de que um operador não dispõe nem dos instrumentos lingüísticos nem dos instrumentos de conhecimento formal, já epistemologicamente legitimados, dominados por um engenheiro ou por um pesquisador. Não pode, portanto, expressar e tampouco compreender a fenomenologia que se desenvolve em seu aparelho cognitivo e que lhe permite, em dadas situações, mediante processos cognitivos já interiorizados e tornados inconscientes, tomar decisões, resolver problemas e lidar com imprevistos que surgem na "rotina" aparentemente contínua da produção em fluxo.

Por outro lado, os engenheiros e pesquisadores não observam a realidade (e, historicamente, não a têm observado) sob o prisma de instrumentos metodológicos que permitam adentrar a essência intangível subjacente aos processos de trabalho objetivos e concretos. Pois, a competência do trabalho "manual desqualificado" está dada nesses níveis invisíveis ao observador, o qual não lê a complexidade por detrás da aparente simplicidade dos fenômenos do trabalho (que aparenta ser exclusivamente manual, rotineiro, parcelado).

A competência cognitiva é algo inacessível a uma observação superficial e, ao mesmo tempo, é algo que atesta a eficiência produtiva desses sistemas que mantêm o trabalho parcelado em seu interior. Vem das competências individuais, no âmbito das habilidades de atuação ("embodiment"), a competência macro da organização.

A falha de observação vem da inobservância de métodos científicos que permitem adentrar a essência da atividade de trabalho, resgatando aquilo que a falha causada pelas distinções de linguagens obliterou ao longo do tempo.

\section{As falhas do observador: mundos paralelos sem conexão}

Em outras palavras, no sistema que opera pela ação do trabalho manual de um coletivo parcelado, há modos peculiares de intercompreensão (entre os atores nele inseridos) e de atividade cognitiva que mobiliza os comporta- 
mentos necessários ao funcionamento do próprio sistema. Entretanto, isso não se torna objetivável, mediante registros simbólicos, pela inexistência dos instrumentos de linguagem e/ou códigos inteligíveis aos observadores externos. O sistema "manual" não possui linguagens que viabilizem o acesso do observador externo ao sistema (engenheiros, pesquisadores, ocupantes de outros cargos isolados do "chão-de-fábrica", etc). Permanece, portanto, enclausurado em seu mundo particular, repleto de percepções e ações que contêm toda uma bagagem fenomenológica de valioso interesse científico. Uma falha ontológica pela falta de instrumentos lingüísticos comuns a dois mundos convencionalmente isolados.

Não há uma linguagem comum que permita aos dois mundos se inter-relacionarem pela mediação dos códigos de ordem simbólica. Significa, portanto, que as ações e razões dos operadores do "trabalho manual", suas mobilizações cognitivas durante a jornada de trabalho na produção das fábricas, não são visíveis aos observadores pelo simples fato de não ser possível, aos próprios operadores, "traduzirem" toda essa fenomenologia cognitiva em uma linguagem propícia à compreensão dos atores de outros domínios de distinções. Estes atores "externos" são os que dispõem do conhecimento formal (engenheiros, pesquisadores, gerentes, consultores externos, etc) e que não conhecem o conteúdo do trabalho "desqualificado", responsável por gerar formas eficientes de operação em ambientes integrados e regidos pela temporalidade do "just-in-time" externo (com a integração on-line, em tempo real, às outras organizações da rede produtiva).

Ora, mas a competência do "trabalho desqualificado" está dada nesse domínio que é inacessível ao conhecimento formal. Eis, assim, uma falha "ontológica" que, historicamente, tem se propagado nos ambientes de produção.

Observe-se isso nas definições de competência, como a que é tecida por Zarifian (1999): Competência consiste em tomar iniciativa em situações eventuais, sabendo mobilizar habilidades para lidar com o novo, com aquilo que o real oferece de incerto, inusitado, imprevisto e que, portanto, foge ao que foi previsto nas prescrições. Para Schwartz (1998), a competência significa possuir iniciativa, mobilizar aspectos de sua própria subjetividade e colocá-la em ação nos cenários da produção; dominar saberes tácitos para ação eficaz; possuir os componentes históricos e aqueles sociais que configuram a competência necessária à ação frente aos ambientes produtivos e possuir, também, os componentes que ativam os próprios sistemas perceptivo e sensorial na solução de panes, defeitos, antecipação às falhas, etc.

No entanto, vale observar que as boas discussões sobre competência, trazidas para o terreno dos sistemas de produção, não tocaram o objeto do presente trabalho.

A dificuldade da "nova" competência em ser caracterizada diz respeito ao seu caráter de "clausura operacional" no interior do sistema cognitivo subjacente à ação do sistema manual, o qual "atua" acoplado ao mundo (MATURANA; VARELA, 1994) configurado pela sua ação incorporada e toda fenomenologia (perceptiva, interpretativa, responsiva) associada a ele.

Tem-se, para melhor esclarecer os termos ora empregados, um "sistema cognitivo" enquanto "sistema autônomo", cujo domínio global de atuaçãoé definido pelas relações de acoplamento dos agentes (MINSKY, 1986) do processo de trabalho (operadores). Postula-se que o observador externo é incapaz de observar este sistema cognitivo em operação porque é incapaz de interatuar no espaço de atuação de tal sistema e, portanto, não compartilha dos mesmos fenômenos de percepção dos agentes operatórios nele acoplados. Não adentra o seu domínio de distinções. Não o pode perceber. É, involuntariamente, cego a ele.

O termo competência cognitiva, aqui, refere-se, portanto, a uma modalidade de competência, inexplorada na literatura pertinente à temática, caracterizada por aquilo que não se oferece facilmente a uma observação limitada aos elementos objetivos das situações dos processos de trabalho analisados; por aquilo que não é dito devido à ausência de condições de expressão dos fenômenos desta competência cognitiva em uma linguagem inteligível ao observador (conforme já discutido anteriormente) e, principalmente, por aquilo que abrange certos fenômenos que escapam ao domínio consciente dos próprios operadores.

\section{A noção de competência cognitiva nos sistemas de operações pesquisados: mundo cognitivo e mundo objetivo dos processos de trabalho}

É incompatível com o desenvolvimento historicamente acumulado pela filosofia da mente (HAUGELAND, 1981; SEARLE, 1981, 1995) e pelas ciências cognitivas (STILLINGS et al., 1995) a pressuposição de que uma atividade de trabalho, qualquer que seja, dotada de componentes cognitivos, possa não mobilizar e/ou desenvolver um tipo peculiar de competência.

Não faz sentido falarmos de cérebros como se eles fabricassem pensamentos da mesma forma como as fábricas produzem carros. A diferença é que os cérebros não podem ser separados dos seus processos criadores. Há memórias, produzidas pelos cérebros, que modificam a si mesmos - e isto quer dizer que os cérebros não podem ser separados dos seus processos criadores. Há memórias, produzidas pelos cérebros, que modificam as formas subsequientes de pensamento (MINSKY, 1986).

A impressão de que nada se adquire de novo nas formas de organização do trabalho que mantêm a especialização parcelada (GORZ, 2001) viola teorias respaldadas pelo 
novo paradigma científico das ciências cognitivas. Rompe, portanto, com o conhecimento científico que já demonstrou que as atividades de caráter manual aparente atuam em interseção com um mundo cognitivo em que o operador se acopla numa relação de mútua especificação. As memorizações no trabalho manual, por exemplo, geram modificações nos operadores e modificam, também, a intencionalidade da ação (WINOGRAD; FLORES, 1986), em consonância com o fato de que "as principais atividades dos cérebros são a produção de modificações neles mesmos" (MINSKY, op. cit.). Um cérebro e a mente emergente não permanecem imutáveis num processo de trabalho, qualquer que seja a sua natureza, inclusive no processo rotineiro e parcelado.

Ainda segundo Minsky (op. cit.), "não podemos confiar no senso comum e seus julgamentos sobre estas questões". Não raro, o senso comum enxerga um mundo objetivo independente do mundo cognitivo do processo de trabalho. Entretanto, toda a ciência contemporânea dos fenômenos cognitivos tem caminhado no sentido de uma noção de "fechamento operacional", aqui útil para a compreensão da competência cognitiva subjacente à rotina parcelada.

Esse "fechamento operacional" do sistema cognitivo é abarcado pelo contexto da própria ação incorporada que lhe confere suporte de sinais, os quais podem ou não adquirir significado no transcorrer da ação operatória. Traz à tona, portanto, as noções de percepção e interpretação como estritamente dependentes dessa ação incorporada em dado contexto. Operador cognitivamente competente, no "trabalho manual", é eficaz na tríade ação-percepção-interpretação.

O que é percebido, no sistema produtivo, e como é interpretado, depende não apenas da história do operador e de seus saberes anteriores, mas de uma competência cognitiva mobilizada em ações específicas conforme o contexto em que estas se desenvolvem.

O sistema cognitivo não permanece inerte ao processo de trabalho parcelado. Entre aqueles que conhecem (sujeitos cognitivos inseridos no sistema) e aquilo que é conhecido (objeto do processo de trabalho) há uma relação de mútua especificação. Os aprimoramentos e aquisições de habilidades e o fomento de uma competência cognitiva resultantes desta relação de co-especificação mútua tornaram-se modos culturais compartilhados de experiência, permitindo a interpretação e atribuições de significados aos elementos e sinais do processo de produção. $\mathrm{O}$ mundo fechado do ambiente operacional cria um ambiente em que as percepções e iniciativas para mudanças de comportamentos (a cada momento) são vivenciadas em um domínio de ação concreta (cujas coordenadas visíveis ao observador são compostas pelos atos manuais) no âmbito de um domínio de distinções consensual, historicamente determinado.

A competência cognitiva depende da inclusão neste mundo fechado (acoplamento), inseparável dos gestos do corpo físico, fazendo emergir uma linguagem e uma competência que, até certo grau, são impenetráveis pelo observador externo (JOHNSON, 1987).

As interpretações do operador só podem ser compreendidas como atuação em um domínio de distinções (sinais, estímulos) que apenas adquirem significação num background de ação concreta sobre os objetos do mundo físico em um suporte de conhecimento abstrato. Isso explica porque um observador externo não pode perceber a mesma coisa que o operador do trabalho manual e, também, porque os sinais captados por ambos (operador e observador) adquirem significados diferentes. Os backgrounds são diferentes de acordo com as distinções de acoplamento (MATURANA; VARELA, 1994) com o mesmo objeto tangível. O operador está a "operar" cognitivamente em um mundo partilhado apenas por aqueles que a ele se acoplam segundo histórias específicas e formas específicas de ação operatória, com todos os seus determinantes de percepção, linguagens e intercompreensão (domínio consensual).

Notáveis discussões sobre as causas e razões dos erros e acidentes nos sistemas produtivos ("erro humano"? "falha"? "problemas/falhas técnicas"?) não conseguem chegar a um consenso porque buscam encontrá-las em um mundo independente da fenomenologia da percepção dos operadores em suas determinantes históricas de acoplamento estrutural (MATURANA; VARELA, 1994) inerentes à ação operatória e seu contexto. Em síntese, essa falta de consenso pode ser atribuída à negligência da noção de "abordagem atuacionista da percepção" ("embodied-enactive approach", termo empregado por Varela, Thompson e Rosch (1993), oriundo da expressão "enação" ou "enaction", em língua inglesa), que envolve a "ação perceptivamente orientada" (MERLEAUPONTY, 2006). Mais ainda, a percepção na produção depende desta ação incorporada ou "embodied action" (JOHNSON, op. cit.; VARELA; THOMPSON; ROSCH, 1993) do operador.

A relação entre o trabalho manual e a atividade cognitiva ganha relevância com o fato, cientificamente legitimado, da inseparabilidade entre percepção e ação nas ciências cognitivas. Pode-se dizer que a ação perceptivamente orientada depende dos comportamentos no nível sensóriomotor. A estrutura sensório-motora (JACKENDOFF, 1987) especifica o modo pelo qual a ação do operador pode ser conduzida por eventos do ambiente.

No "trabalho manual", o exercício da competência cognitiva (desvinculada dos indicadores convencionais que tradicionalmente têm rotulado também as qualificações para o trabalho) não é independente da ação. Os sistemas sensorial e motor estão atrelados à ação perceptivamente orientada do operador. Aquilo que o observador externo "enxerga" é diferente daquilo que o operador "enxerga" porque estão acoplados em mundos diferentes de ações diferentes. Tornase mais claro, portanto, porque a competência cognitiva 
do operador não tem sido visível ao observador externo e, também, porque explicações sobre "falhas" e a caracterização de "erro humano", feitas pelo observador, não condizem com a realidade da ação e das percepções dos operadores envolvidos na "falha" e no suposto "erro humano".

Agentes, para adotarmos a mesma conotação atribuída por Minsky (1986), no presente caso, atuantes como operadores inseridos no processo de trabalho ou como profissionais de planejamento-concepção das tarefas (nas plantas investigadas, são os engenheiros de controle e automação e os engenheiros de processo), acoplados em mundos distintos, não percebem um mesmo objeto da mesma forma. A maneira específica de se imbuir na ação determina a percepção do agente conforme níveis distintos de comportamento. Ou seja, "o comportamento é a causa de todas as estimulações" (MERLEAU-PONTY, 2006). Os sinais percebidos e sua interpretação (conversão para o domínio simbólico) dependem do mundo ativo específico em que o agente se encontra acoplado. Em síntese, engenheiro e operador não percebem e interpretam da mesma forma um mesmo sinal do mundo físico porque estão acoplados em domínios distintos de atuação (MATURANA; VARELA, 1994; VARELA, 1979).

A competência cognitiva não preexiste independente da forma e do conteúdo da tarefa, mas possui um caráter atuado emergente (VARELA, 2000) em situações particulares de ação nos processos de trabalho.

\section{Falha ontológica da noção de representação em ergonomia cognitiva}

A noção de representação mental como um espelhamento de partes de um mundo objetivo, exterior e com propriedades predeterminadas, independente da história e da estrutura cognitiva do agente, é uma falha ontológica. $\mathrm{O}$ agente cognitivo não é um receptor de inputs de um mundo objetivo exterior e emissor de outputs resultantes de processamento mecânico das informações. Situações de fratura (WINOGRAD; FLORES, 1986) têm demonstrado, nos sistemas de produção, que tal noção não consegue explicar a verdadeira estrutura responsável pelas disfunções e falhas, as quais acabam por ser incorretamente taxadas de "erro humano" de um "fator humano" (DEJOURS, 1995).

Um observador sempre irá classificar panes e acidentes como resultados de falha ou erro humano, porque o mundo do observador não é o mesmo do operador que supostamente falhou ou errou. A realidade do segundo é imperceptível ao primeiro.

A atuação ("embodied-action") em um mundo cognitivo, pelo operador, gera uma interdependência entre ação e percepção, fruto do acoplamento estrutural (MATURANA; VARELA, 1994) ao qual o observador não consegue ter acesso, pelo fato de estar envolvido em outro acoplamento distinto, com outras determinações, inerentes a ele, de ação e percepção.

Há uma falha ontológica na noção de representação operatória, ao pressupor a existência de um mundo predeterminado independente das noções de ação incorporada, atuação (em ciências cognitivas) e acoplamento estrutural ao processo de trabalho. Apenas uma descrição da atividade baseada nos elementos do mundo objetivo, supostos como sendo captados e percebidos pelo operador (inputs/outputs), não consegue explicar como e porque alguns sinais não são captados nem percebidos, gerando falhas de qualidade, panes e acidentes. A capacidade de percepção destes sinais eventuais é um dos elementos (Quadro 1) da dita competência cognitiva latente e tácita que emerge como resultado da atuação no processo de trabalho parcelado.

Do mesmo modo que há fraturas/falhas ontológicas graves nas abordagens que rotulam alguns trabalhos como manuais e desqualificados, há uma propagação destas falhas até às noções convencionais de representação para a tomada de decisão, que não explicam as lacunas de intercompreensão entre agentes da produção envolvidos num mesmo sistema de produção, separados em domínios de distinção diferentes (Figura 1). Maturana e Varela (1994) utilizam o conceito de "domínio de distinção" ou de "ontologias constitutivas" para explicar este fator determinante de uma percepção compartilhada, cuja aplicação nos sistemas de produção investigados é apresentada a seguir.

Os atos dos agentes de produção situados em domínios de distinções diferentes $\left(\mathrm{D}_{\mathrm{o}}\right.$ : Domínio operacional e $\mathrm{D}_{\mathrm{p}}$ : Domínio de planejamento) não são inteligíveis entre um e outro agente, situados e isolados que estão em seus diferentes domínios $\left(D_{o} \neq D_{p}\right)$. Ou seja, os atos de agentes situados em $\mathrm{D}_{\mathrm{o}}$ não são percebidos, interpretados e compreendidos da mesma maneira pelos agentes situados em $D_{p}$ e vice-versa (Figura 1). O resultado deste fenômeno são as insólitas noções de falha, de erro humano, de representação operatória (e de um suposto "fator humano" (DEJOURS, 1995) determinante da falibilidade dos sistemas operacionais).

Já se provou, há bastante tempo, nas ciências cognitivas, que a percepção é um processo ativo e não um espelhamento de um ambiente predeterminado. A filosofia de Merleau-Ponty $(1976,2006)$ também afirmou este caráter ativo da percepção. Ou seja, a percepção não se situa em nenhuma estrutura não-experiencial do mundo físico objetivo, mas resulta de uma experiência corporificada imbricada na ação.

Este mundo operatório, e suas percepções, resultam do domínio de ação, arraigada também nas estruturas sensório-motoras ativadas pelo processo de trabalho. Não há como o observador partilhar deste mundo, estando atuante em outro domínio de ação (Figura 1). 


\section{Métodos de pesquisa: [A.E.T.] - [C.W.A.]}

A Análise Ergonômica do Trabalho-A.E.T. (WISNER, 1987; GUÉRIN et al., 2002), com adaptações para o objeto proposto, mostrou-se uma alternativa satisfatória para a consolidação da base empírica do presente programa de pesquisa. Técnicas de entrevista para "análise do trabalho cognitivo", segundo o modelo da Cognitive Work Analysis - C.W.A. (VICENTE, 1999), foram associadas à A.E.T. Isso ocorreu principalmente na $4^{a}$ fase das análises.

A razão da conciliação de A.E.T. e C.W.A. se deveu à riqueza fornecida pela multiplicidade dos métodos englobados pelos dois "blocos metodológicos", situados em domínios distintos de observação, registro e análise dos dados. Essa "riqueza dos métodos" pode ser comprovada pela sua fértil propriedade em: I) gerar um vasto volume de dados empíricos e, principalmente, II) pela viabilização, conforme os postulados da "boa ciência", da formulação de enunciados científicos válidos para generalização em diversos casos (POPPER, 2002; LAKATOS, 1999; KUHN, 1996). Isso pode ser verificado, a qualquer momento, em qualquer ambiente produtivo que se escolha, por qualquer membro da comunidade científica que deseje verificar as teses apresentadas neste trabalho, desde que adequadamente munido dos instrumentos metodológicos pertinentes ao presente objeto de pesquisa.

Pelo uso de dois "blocos" de métodos que possuem, em comum, a procura por aprofundar, qualitativamente, na essência de cada situação investigada, com profundidade no nível dos detalhes, foi possível registrar explicações condizentes a uma formulação mais abrangente de enunciados científicos ("verdadeiros", cf. filosofia da ciência...) e explicativos, válidos em extenso número de casos. As verificações podem ser feitas por outros membros da comunidade científica, visto que as fases para tal são fornecidas neste trabalho científico.

As fases de observações sistemáticas puderam ser classificadas em quatro "domínios de observação", distintos, a saber:

a) identificação das situações correspondentes a tarefas prototípicas;

b) análise da atividade no domínio do trabalho concreto observável;

c) análise da atividade no domínio das tomadas de decisão; $\mathrm{e}$

d) análise detalhada do trabalho cognitivo.

$\mathrm{Na}$ fase a), de identificação das situações correspondentes a tarefas prototípicas, a aquisição e a análise de dados basearam-se na observação e na descrição detalhada de um extenso volume de situações específicas. Por exemplo, todos os atos e tempos característicos de uma determinada tarefa, com suas condições de contorno dadas pelas especificidades das situações (p.ex., início de um período, dentro do ciclo de rodízio, com um outro operador).
$\mathrm{Na}$ fase b), os registros começaram a envolver uma maior contextualização. Nesta fase de análise da atividade no domínio do trabalho concreto, os operadores e as tarefas observados foram sempre os mesmos, envolvendo a singularização dos dados e análises. Os trabalhadores observados foram divididos em 14 pequenos grupos, e foram analisadas 5 tarefas diferentes, executadas por esses 14 grupos.

$\mathrm{Na}$ fase c), de análise das tomadas de decisão, o objetivo foi responder, com base nos registros das fases anteriores, as questões: "o que" - "como" - "porque". As prioridades e escolhas foram analisadas, sob o background das fontes de informações disponíveis. Iniciou-se a investigação das heurísticas e das regras implícitas na ação. Entrevistas focalizadas na situação, em seu contexto de "situated action", foram empregadas.

$\mathrm{Na}$ fase d), foram focalizadas as situações que fugiam dos procedimentos do tipo "se" - "então" previstos pela organização do trabalho prescrito. Ou, melhor dizendo, situações em que as prescrições do tipo "se" - "então" não eram suficientes para garantir uma ação adequada à manutenção da produção em sua aparente continuidade. São as seguintes situações (listadas de i a iii): i) Peça com "aspecto ok", segundo as "conformidades", mas que, entretanto, fora excluída como "não-conformidade" - Como o operador soube disso? - A fase d) estendeu as entrevistas até o alcance de uma compreensão satisfatória dessas ações; ii) Busca de informações fora do posto de trabalho - "O que você precisou saber quando foi até o..." - "E se não fosse possível saber..., faria..."; iii) Situações em que ocorria uma "lentidão" na operação cognitiva - Ampliação do tempo de inspeção, ampliação no tempo gasto para observar um dado indício; ampliação do tempo de um determinado ato - "o que está acontecendo?"; "o que você está observando?" - "o que está diferente aí nessa peça?"; "isso está fora?"; "o que acontece se deixar passar assim?”; “... se deixar assim...”; "se você não visse, ia ocorrer..."; "se encaixar do jeito que é normal, ia acontecer que..."; "por que teve que fazer diferente...".

Em todas as fases, a análise partiu dos comportamentos objetivos observados e registrados, até alcançar as suas razões e motivos pelas verbalizações, pilares comuns à A.E.T e à C.W.A. Os dois lados foram confrontados e a validação das hipóteses surgiu pela "autoconfrontação" (WISNER, op. cit.; GUÉRIN et al., op. cit.), no caso da A.E.T., e pela verificação no domínio das "Worker Competencies" da C.W.A. (VICENTE, 1999).

\section{Resultados e discussões}

O Quadro 1 reúne algumas das habilidades dependentes da atuação do trabalhador ou habilidades atuacionistas.

Durante a realização dos métodos de pesquisa, foi feita a caracterização das "habilidades atuacionistas" ou habilidades reais que formam um "verdadeiro conteúdo" 
invisível no trabalho que parecia ser "sem conteúdo", mas que, na realidade, esconde habilidades complexas, necessárias à manutenção da produção sem falhas. As habilidades atuacionistas fazem o processo de trabalho funcionar de modo contínuo e em fluxo.
O Quadro 2 condensa alguns dados objetivos sobre percepções dos observadores em confronto com o conteúdo real das tarefas, conforme percepção dos trabalhadores e análises objetivas das observações sistemáticas aliadas às entrevistas de autoconfrontação.

Quadro 1. Caracterização das "habilidades atuacionistas" ou habilidades reais que formam um "verdadeiro conteúdo" invisível no trabalho real. Elementos que caracterizam as Habilidades Atuacionistas (Habilidades Reais) nos processos de trabalho analisados

1. Habilidades que emergem conforme as tarefas executadas pelo trabalhador: Percepção de pequenos defeitos; identificação de correções necessárias; decisão ágil pelo descarte de determinadas peças com qualidade incerta;

2. Habilidades cognitivas de percepção - Dependem dos movimentos e gestos do corpo físico: - Agilidade e eficiência na inspeção visual de peças para carrocerias de automóveis;

3. Tomada de iniciativa de reduzir ou aumentar a cadência dos atos motores com vistas ao alcance de resultado futuro;

4. Habilidades de percepção de indícios de sutis desvios de qualidade ("imperceptíveis" ao observador/agente externo), como alterações de formatos de peças e/ou problemas de encaixe, pequenos defeitos de materiais de carrocerias de veículos;

5. Tomada de decisão, na temporalidade restrita do processo de trabalho, referente ao descarte ou correção de peças "suspeitas" de defeito;

6. Habilidades para lidar com as dificuldades de coordenação da prática e de encadeamento dos gestos postos pela fragmentação excessiva das tarefas;

7. Habilidades para lidar com as dificuldades de comparações e analogias entre a situação do momento e situações pretéritas;

8. Habilidades para lidar com as dificuldades na percepção de similaridades ou distinções entre situação presente e situações pretéritas;

9. Tomada de iniciativa para a troca / compartilhamento de informações à revelia dos ditames de fragmentação da organização do trabalho prescrito; e

10. Habilidades para lidar com as dificuldades de ação reflexiva e de troca de informações necessárias à manutenção do fluxo produtivo e da continuidade da produção.

Quadro 2. [Habilidades Aparentes - Abordagem Cognitivista] x [Habilidades Reais - Abordagem Atuacionista ou "embodied-enactive view"].

\section{Habilidades Aparentes}

1. Definição e caracterização são exteriores aos agentes;

2. Visíveis, tangíveis, de fácil objetivação;

3. Idéia de representação de um mundo exterior independente do agente: Processamento inadequado da informação de um mundo exterior objetivista interrompe o fluxo da produção (noção de "representação mental incorreta");

4. O que é trabalhar, segundo noção de eventos e de habilidades aparentes? Consiste em antecipar-se aos eventos, pressenti-los e enfrentá-los para retomar a produção segundo os critérios previstos de normalidade;

5. Modelo de operador que pressupõe: Processador de informações; elaborador de representações; receptor de indícios; percepção é passiva e determinada por um ambiente exterior; Processos cognitivos são vistos como processamento simbólico de informações do ambiente;

6. Interação agente-ambiente:

Simples, do tipo no qual o ambiente determina as respostas do agente; o agente processa os seus estímulos objetivos exteriores - Por exemplo: pressupõe que o agente deve permanecer atento ao ambiente e a seus estímulos para organizar e conduzir a ação conforme sua determinação. $\mathrm{O}$ agente é um receptor passivo; e

7. Exemplos de mobilização visível das habilidades aparentes: Habilidades para lidar com: panes, defeitos de equipamentos, quebras, incidentes, acidentes, disfuncionamentos, desvios de qualidade, falta de materiais, mudanças imprevistas na programação de fabricação, encomendas repentinas, aumento de rejeitos, aumento de filas, gargalos, intempéries; pedido inusitado de um cliente; nova expectativa de um cliente; problema novo posto por um cliente, necessidade de um novo produto.
Habilidades Atuacionistas segundo o ponto de vista de uma Abordagem atuacionista da atividade cognitiva

1. Definição e caracterização dependem da atuação dos agentes;

2. Invisíveis, intangíveis, de difícil objetivação;

3. Não existe a representação de um mundo exterior: Existe a construção de um mundo pelo acoplamento estrutural do agente, por meio de redes sensório-motoras ativadas na ação incorporada (embodied action). Cognição depende da ação;

4. O que é trabalhar, segundo a noção de atuacionismo? Consiste em acoplar-se a um domínio específico de atuação e variar os níveis de controle da ação para fazer a rotina funcionar na normalidade;

5. Modelo de operador que pressupõe: Agente cognoscitivo atuante por ação incorporada; percepção é intencional (PACHOUD, 2000), ativa e depende da ação; abordagem atuacionista ("embodied-enactive approach"): Processos cognitivos são resultantes da ação incorporada ou atuação dos agentes;

6. Interação agente-ambiente:

Complexa, do tipo co-determinação (especificação mútua); estrutura do acoplamento do agente determina as suas "respostas" - Por exemplo: pressupõe permanecer atuante no processo concreto de trabalho, de forma a "manter-se situado" e fazer emergir a ação eficaz: atuacionismo ou "embodied-enactive approach". O agente é atuante; e

7. Exemplos de mobilização invisível das habilidades atuacionistas: Agente "frio" e ainda "não-situado", quando assume o posto de trabalho, necessita ativar as habilidades atuacionistas para agir corretamente; habilidades para lidar com: a) sobrecarga na memória de trabalho devido à distribuição e fragmentação arbitrária de tarefas e informações; b) fadiga mental após período " $x$ " no mesmo posto; c) impossibilidade de troca de informações (imobilização física); d) dificuldades para comparações e analogias entre situações; e) dificuldades de coordenação da prática e encadeamento de atos no processo de trabalho; e f) dificuldades para alterações das condições de ação. 
O Quadro 3 estabelece uma correlação entre o ponto de vista do observador externo, o qual percebe apenas as "habilidades aparentes" das tarefas (Conforme já apresentado no Quadro 1), e o ponto de vista dos próprios trabalhadores, os quais se valem de habilidades muito mais complexas que as habilidades aparentes - As habilidades atuacionistas. O Quadro 3 permite, também, confrontar a abordagem "cognitivista" que enxerga o trabalhador como um "processador de informações", e a abordagem "atuacionista" ("embodied-enactive view"), que demonstra a existência de uma atividade fortemente impregnada de componentes cognitivos complexos envolvidos na percepção e tomada de decisão em situações de ação.

\section{Conclusão}

O presente trabalho de pesquisa é tão somente um ponto de partida. O início de uma ruptura com um antigo ponto de vista (cognitivista, representacionista) e a transição para um novo olhar (atuacionista, incorporado: "embodied-enactive view") sobre o trabalho e a ação nos sistemas contemporâneos de produção.

Um olhar ao qual não se permite mais excluir o próprio fenômeno da observação (i.e., o observador). Pois, toda falha ontológica historicamente verificada, anterior- mente caracterizada nas páginas deste texto, está alocada justamente nos fenômenos de observação daquilo que é aparente e na não-percepção daquilo que é essencial.

$\mathrm{O}$ ponto de partida está dado pelo apontamento e pela caracterização de um mundo geralmente imperceptível ao observador da ciência. Um mundo fechado em si mesmo, repleto de fenômenos que justificam a continuidade e a eficácia de sistemas de produção, os quais alojam a descontinuidade do gesto humano realizado em tarefas fragmentadas.

Se a descontinuidade do gesto não interrompe a continuidade do sistema produtivo, isso se deve à premência do sistema cognitivo subjacente aos gestos visíveis do processo de trabalho. Sistema cognitivo auto-referente, que faz emergir uma noção de competência até então desconhecida. Trata-se da competência cognitiva cujas manifestações objetivas dependem da atuação ou "embodiment" do operador.

Este sistema não opera e nunca operou por representação de um mundo objetivo predeterminado, mas sim por ação incorporada (perceptivamente orientada) de caráter atuacionista. Eis a falha: Observador isolado do objeto observado pelas distinções de atuação. A ruptura: Gerar conhecimento levando em conta, na própria observação, as distinções de atuação entre observador e objeto observado.

Quadro 3. Tarefas e seus conteúdos "Aparente" e "Real".

\begin{tabular}{|c|c|c|c|}
\hline Grupo-Tarefa & Tarefa & Habilidades aparentes & $\begin{array}{c}\text { Habilidades } \\
\text { Atuacionistas } \\
\text { do Quadro 1 } \\
\end{array}$ \\
\hline G1-T1 & Encaixe-Fábrica de tubulações & Destreza; velocidade + agilidade de encaixe & $1-3,8,9$ \\
\hline G2-T1 & Encaixe-Fábrica de tubulações & Destreza; velocidade + agilidade de encaixe & $1-3,8,9$ \\
\hline G3-T2 & Inserção/colocação de peças - Fábrica de espumas & $\begin{array}{l}\text { Decisão rápida sobre qual arame usar; velocidade } \\
\text { ao colocar o arame; velocidade de deslocamento } \\
\text { entre os moldes da esteira }\end{array}$ & $1-4,6,7,10$ \\
\hline G4-T2 & Inserção/colocação de peças - Fábrica de espumas & $\begin{array}{l}\text { Decisão rápida sobre qual arame usar; velocidade } \\
\text { ao colocar o arame; velocidade de deslocamento } \\
\text { entre os moldes da esteira }\end{array}$ & $1-4,6,7,10$ \\
\hline G5-T2 & Inserção/colocação de peças - Fábrica de espumas & $\begin{array}{l}\text { Decisão rápida sobre qual arame usar; velocidade } \\
\text { ao colocar o arame; velocidade de deslocamento } \\
\text { entre os moldes da esteira }\end{array}$ & $1-4,6,7,10$ \\
\hline G6-T2 & Inserção/colocação de peças - Fábrica de espumas & $\begin{array}{l}\text { Decisão rápida sobre qual arame usar; velocidade } \\
\text { ao colocar o arame; velocidade de deslocamento } \\
\text { entre os moldes da esteira }\end{array}$ & $1,4,6,7,10$ \\
\hline G7-T3 & Furação-Fábrica de carrocerias & Destreza; Força física & $1-4,8$ \\
\hline G8-T3 & Furação-Fábrica de carrocerias & Destreza; Força física & $1-4,8$ \\
\hline G9-T4 & Embalagem-Fábrica de carrocerias & Rapidez gestual & $1-5$ \\
\hline G10-T4 & Embalagem-Fábrica de carrocerias & Rapidez gestual & $1-5$ \\
\hline G11-T4 & Embalagem-Fábrica de carrocerias & Rapidez gestual & $1-5$ \\
\hline G12-T5 & Inspeção Final - Fábrica de carrocerias & $\begin{array}{l}\text { Conhecimento de defeitos típicos } \\
\text { Rapidez na identificação de defeitos típicos }\end{array}$ & $1,2,4,5,7-10$ \\
\hline G13-T5 & Inspeção Final - Fábrica de carrocerias & $\begin{array}{l}\text { Conhecimento de defeitos típicos } \\
\text { Rapidez na identificação de defeitos típicos }\end{array}$ & $1,2,4,5,7-10$ \\
\hline G14-T5 & Inspeção Final - Fábrica de carrocerias & $\begin{array}{l}\text { Conhecimento de defeitos típicos } \\
\text { Rapidez na identificação de defeitos típicos }\end{array}$ & $1,2,4,5,7-10$ \\
\hline
\end{tabular}




\title{
Enaction and work process: an embodied-enactive approach of the operating-action
}

\begin{abstract}
Based on the new paradigm of cognitive sciences, this paper deals with an ontological rupture having an objectivist approach to the Operating-Representation in cognitive ergonomics. Actuationism is an embodied-enactive view. According to this approach, cognitive processes are seen as emerging or enacted by situated agents (workers). The Actuationistic approach is important underpinning various contributions in ergonomics. This work is the result of research done on real production systems using an ergonomic work analysis. It identified and characterized an ontological failure present in the operating-activity analysis: An isolated observer observing the object by the actuation distinguishes between them. This results in perception, interpretation and action differences, which, historically, have made an in-depth knowledge about how the work process functions impracticable. Currently, the processes, which seemed to be like routines, approach a new competence notion, the actuationistic or cognitive competence, necessary to deal with the continuity and flow in productive processes.
\end{abstract}

Keywords: Enactive approach. Cognitive ergonomics. Embodied action.

\section{Referências bibliográficas}

DEJOURS, C. Le Facteur Humain. Paris: Presses Universitaires de France, 1995. 128 p.

GORZ, A. Crítica da divisão do trabalho. 4. ed. São Paulo: Martins Fontes, 2001. 248 p.

GUÉRIN, F. et al. Compreender o trabalho para transformá-lo: a prática da Ergonomia. São Paulo: Edgard Blücher, 2002. 224 p.

HAUGELAND, J. (ed.). Mind design: Philosophy psychology, artificial intelligence. Cambridge, Massachusetts: MIT Press, $1981.362 \mathrm{p}$

JACKENDOFF, R. Consciousness and the Computational Mind. Cambridge: MIT Press, 1987. 468 p.

JOHNSON, M. The body in the mind: the bodily basis of imagination, reason and meaning. Chicago: University of Chicago Press, 1987. 234 p.

KUHN, T. S. The structure of scientific revolutions. 3. ed. Chicago: Chicago University Press, 1996. 278 p.

LAKATOS, I. Falsificação e metodologia dos programas de investigação científica. Lisboa: Edições 70, 1999. 208 p.

LAMMING, Richard. Beyond partnership: strategies for innovation and lean supply. New York: Prentice Hall, 1993. $302 \mathrm{p}$.

MATURANA, H.; VARELA, F. De maquinas y seres vivos: autopoiesis, la organización de lo vivo. Santiago: Editorial Universitaria, 1994. 122 p.

MERLEAU-PONTY, M. A estrutura do comportamento. São Paulo: Martins Fontes, 2006. 376 p.

Phenomenologie de la perception. Paris: Gallimard, 1976. $560 \mathrm{p}$.

MINSKY, M. The Society of Mind. New York: Simon and Schuster, 1986. 340 p.

PACHOUD, B. The teleological dimension of perceptual and motor intentionality. In: PETITOT, J. et al. (Ed). Naturalizing phenomenology: Issues in contemporary phenomenology and cognitive science. Stanford: Stanford University Press, 2000. p. 196-202.
PETITOT, J. et al. (ed). Naturalizing phenomenology: Issues in contemporary phenomenology and cognitive science. Stanford: Stanford University Press, 2000. 641 p.

POPPER, K. R. The logic of scientific discovery. London: Routledge Classics, 2002. 544 p.

SCHWARTZ, Y. Os ingredientes da competência: um exercício necessário para uma questão insolúvel. Educação \& Sociedade, São Paulo, v. 2, n. 65, p. 101-139, dez. 1998.

SEARLE, J. Minds, brains and programs In: HAUGELAND, J. (ed.). Mind design: philosophy, psychology, artificial intelligence. Cambridge: MIT Press, 1981. p. 183-204.

Intencionalidade. São Paulo: Martins Fontes, 1995. $408 \mathrm{p}$.

STILlingS, N. et al. Cognitive Science: an introduction. 2. ed. Cambridge: The MIT Press, 1995. 544 p.

VARELA, F. Principles of biological autonomy. New York: Elsevier, 1979. 583 p.

The specious present: A neurophenomenology of time consciousness. In: PETITOT, J., et al. (ed). Naturalizing phenomenology: Issues in contemporary phenomenology and cognitive science. Stanford: Stanford University Press, 2000. p. 266-306.

VARELA, F.; THOMPSON, E.; ROSCH, E. Embodied Mind: cognitive science and human experience. New York: MIT Press, 1993. 308 p.

VICENTE, K. Cognitive work analysis: toward safe, productive and healthy computer-based work. New Jersey: Lawrence Erlbaum Associates, 1999. 392 p.

WINOGRAD, T.; FLORES, F. Uderstanding computers and cognition. Massachussets: Addison-Wesley, 1986. 207p.

WISNER, A. Por dentro do trabalho: ergonomia - método e técnica. São Paulo: FTD-Oboré, 1987. 189 p.

ZARIFIAN, P. Objectiv Compétence. Paris: Liasons, 1999. $229 \mathrm{p}$. 


\section{Sobre os autores}

\section{Gilbert Cardoso Bouyer}

Campus Avançado de João Monlevade, Departamento de Ciências Exatas e Aplicadas - DECEA,

Universidade Federal de Ouro Preto - UFOP,

Rua 37, 115, Loanda, CEP 35930-000, João Monlevade, MG, Brasil,

e-mail: gilbertcb@uol.com.br

\section{Laerte Idal Sznelwar}

Departamento de Engenharia de Produção,

Escola Politécnica da Universidade de São Paulo - PRO/POLI,

Universidade de São Paulo - USP,

Av. Prof. Almeida Prado, 128, CEP 05508-900, Cidade Universitária, São Paulo, SP, Brasil,

e-mail: laertesz@usp.br

Recebido em 16/6/2005

Aprovado em 05/10/2006 